\title{
Predicting ecological resilience of marine benthic communities facing a high risk of oil spills
}

\author{
J. Kotta ${ }^{1}$, R. Aps ${ }^{1} \&$ K. Herkül ${ }^{1,2}$ \\ ${ }^{I}$ Estonian Marine Institute, University of Tartu, Tallinn, Estonia \\ ${ }^{2}$ Institute of Zoology and Hydrobiology, University of Tartu, Tartu, \\ Estonia
}

\begin{abstract}
Ecosystem resilience emphasizes two different aspects of stability, i.e. the capacity of an ecosystem to tolerate disturbances (sensitivity) and rebuild itself when necessary (recovery). This paper examines the relationships between the magnitude of oil spill and the resilience of benthic invertebrate communities in the Gulf of Finland, Baltic Sea during 2006-2007. We analyzed whether and how depth, sediment type, topographic structure and exposure contributed to these relationships. Predictive spatial modelling was used to extrapolate the sensitivity of benthic invertebrate communities into the whole gulf scale based on the knowledge of the combined effects of environmental variability, oil exposure and biotic patterns. Predictive modelling provides managers with a useful and cost-efficient tool in reducing the potential oil spill related environmental risk by, e.g., redirecting shipping away from sites that have high sensitivity and low recovery potential, and by allocating sufficient oil combating resources to protect those areas in the case of oil accident.
\end{abstract}

Keywords: Baltic Sea, benthic invertebrates, recovery, sensitivity.

\section{Introduction}

Oil spills are ranked among the major threat to the stability of marine environment and can have severe impacts on nearshore biodiversity and functioning [1]. Accidental spills coat the shoreline with oil leading to immediate impacts $[2,3]$ whereas responses are more subtle and less known in subtidal 
habitats, though, the effects may last up to 20 years after the spill $[4,5]$. The recent drastic spills indicate that oil combat management has failed to achieve environmental sustainability partly because of insufficient generic understanding of how spills impact nearshore biota on another side. This uncertainty in predictions can be reduced by incorporating physical environment and community ecology (i.e. functionality of biota) into ecosystem models. In order to do so we need (1) to establish functional relationships between the magnitude of oil spill and the resilience of coastal biota and (2) estimate how environmental variability modulates ecosystem response to oil spills. Such estimates are of utmost value in a situation of increasing shipping and the related risk of oil accident. For example it is estimated that the amount of oil transported in the Baltic Sea area exceeds the current values more than 1.5 times by 2015 [6].

Ecosystem resilience emphasizes two different aspects of stability i.e. the capacity of an ecosystem to tolerate disturbances (sensitivity) and rebuild itself when necessary (recovery). Sensitivity quantifies the magnitude of disturbance that can be absorbed before the system changes its structure by changing the variables and processes that control behaviour. On the other hand, recovery refers to the rate at which a system returns to a single (or multiple) steady or cyclic state following a perturbation [7]. Oil spills are known to have the dual effect on coastal environment. The same spill can raise the biomass levels of less sensitive species due to organic enrichment and decrease the biomass of sensitive species because of toxicity $[8,9]$. Following the bloom of opportunists and the decline of sensitive species a period of recovery returns the communities to a characteristic of relatively undisturbed conditions [10, 11]. Environmental variability directly affects the impact of spills: the sites that are well protected from waves appear particularly susceptible to adverse impacts of oil [12]. Besides direct effects, environmental variability is known to affect community structure and, as sensitivities of animals vary among species, the response of communities to oil spills is likely to change with environmental settings. Despite of this we are not aware of any studies on the interactive effects of physical forcing and oil spills to nearshore ecosystems.

Benthic invertebrate communities represent an intermediate trophic level and they are highly sensitive to a range of environmental forcing factors [10,13]. Oil spills potentially affect benthic communities in many ways e.g. through modification of habitat characteristics, suffocation and/or toxification of flora and fauna and removal of the key habitat forming species that may indirectly affect other components of benthic life [1]. Owing to their feeding mode, suspension-feeders are directly linked to pelagic productivity [14] and benthic grazers to the production of benthic micro- and macroalgae $[15,16]$ while deposit-feeders rely on sedimenting debris or degrading filamentous algae [17]. Besides feeding functions, animal mobility determines the response of species to environmental forcing. Mobile species possess the ability to escape direct smallscale physical disturbances and perform an active search for food. Sessile species are more susceptible to physical disturbances than mobile species and rely completely on local food levels [19]. Consequently, different functional groups are influenced by different environmental factors and this difference may explain 
a high degree of variability in the response of benthic invertebrate communities to oil spills $[11,19,20]$.

In January 2006 an extensive oil spill was detected in the northeastern Baltic Sea. Due to the severe storms removal of the oil from the sea surface was aggravated and much of oil found its way into embayments of the western Gulf of Finland. According to the preliminary field survey it was estimated that approximately 10 t of heavy oil stranded to the shores of Keibu and Nõva Bays [21] and it is not known how much settled in subtidal areas. In this study we described the effect of the oil spill on benthic invertebrate communities. As there were good pre-spill data on the benthic invertebrate communities we were able to evaluate the impacts using proper Before-After Control-Impact design [22]. By comparing pre-spill, spill and post-spill data we examined which environmental factors were responsible to sensitivity and recovery of communities and then using predictive spatial modelling extrapolated the knowledge into the Gulf of Finland scale.

\section{Material and methods}

The benthic invertebrate sampling and sample analysis followed the guidelines developed for the HELCOM COMBINE programme [6]. The field works were performed immediately after the spill in 2006 and a year after in 2007. The macrozoobenthos sampling and material processing followed an earlier monitoring study in respect to sampling grid, grab type, sieving, field assistants and laboratory procedures [23]. Sediment and macrozoobenthos sampling was performed by an Ekman type bottom grab $\left(400 \mathrm{~cm}^{2}\right)$. A total of 63 stations were sampled and three replicate samples were taken in each station.

Macrozoobenthos samples were sieved through a $0.25 \mathrm{~mm}$ mesh and the residuals were preserved in a deep freezer at $-20{ }^{\circ} \mathrm{C}$. In the laboratory, animals were counted and identified under stereo dissecting microscope. Dry weights of each taxon were obtained after keeping the material 48 hours at $60{ }^{\circ} \mathrm{C}$. Macrozoobenthos was classified into feeding guilds - deposit feeders, suspension feeders and herbivores based on literature [24] and earlier field observations.

As other natural factors may confound the response of invertebrates to oil spill we included the measurement of the key environmental variables in the design. During sampling we recorded depth and the type of bottom substrate. Based on depth charts (available at the Estonian Marine Institute) the inclination of coastal slopes was calculated at 100 and 1,000 m resolutions using the Spatial Analyst tool of ArcInfo software [25]. High values of coastal slopes indicate the occurrence of topographic depressions at the measured spatial scale. Low values refer to flat bottoms. Exposure was assessed as an aspect of slope and the nearest distance of sampling point to $20 \mathrm{~m}$ isoline. Oiled areas were identified based on the winter 2006 oil survey maps [21].

Multivariate data analyses were performed by the statistical program "PRIMER" version 6.1.5 [26]. Invertebrate biomass data were square-root transformed to down weigh the dominant species and increase the contribution of 
rarer species in the multivariate analysis. The second stage BEST analyses were used to evaluate how environmental variability contributed to the magnitude of impacts and recoveries of benthic invertebrates. The BEST analysis shows which environmental variables best predict the observed biotic patterns (i.e. temporal variability). During analyses the temporal dynamic of invertebrate communities was quantified separately at each station by using a zero-adjusted Bray Curtis coefficient. The coefficient is known to outperform most other similarity measures and enables samples containing no organisms at all to be included [27]. The resulting dissimilarity values were then combined to test for an overall effect of oil spill and other environmental variables in the temporal variability of benthic invertebrate communities. Comparisons between pre-spill and spill data gave an indication of impacts and differences between pre-spill and post-spill data that of recoveries, respectively. A Spearman rank correlation (r) was computed between the similarity matrices of environmental data (Euclidean distance, environmental variables were normalized prior to analyses) and different invertebrate communities (Bray-Curtis coefficient, biotic data was square-root transformed). A global BEST match permutation test was run to examine the statistical significance of observed relationships between environmental variables and biotic patterns. The environmental variables that were selected as significant in the BEST analyses were used in spatial modelling.

General Additive Model was used to model the impact and recovery of benthic invertebrate communities to oil spill in the southern coastal area of the Gulf of Finland. GRASP software (Generalized Regression Analysis and Spatial Prediction) version 3.3 for S-Plus [28, 29] was used to make spatial predictions of several response variables using point surveys of the response and predictor variables. Stepwise (only best predictors selected) models were tested. The models were run with 2 degrees of freedom and the conservative Akaikes Information Criterion was used to select variables into the model.

In the spatial models the "impact" was defined as a statistically significant difference in the biomass structure of invertebrate communities between contaminated area (impact) and other sites that were not contaminated (control) in 2006 and "recovery" as the disappearance of such difference in 2007. The statistical differences were assessed using ANOSIM analysis in the PRIMER statistical package. We based comparisons on paired sites in order to reduce the significant effect of environmental variables among sites. Reference sites were selected to match impact sites in environmental features (i.e. depth, sediment type, slope, aspect, exposure). These matched pairs were assumed to be similar in respect to environmental variables that affect the resource of invertebrates. Thus, any difference in matched pairs is presumed to be due to exposure to oil spill at impact site. Prior to analyses the assumption of equality of matched pairs was verified using the existing pre-spill data.

\section{Results}

Altogether 34 taxa of infaunal and epifaunal invertebrates were collected in the study area. The communities were dominated by a variety of bivalve molluscs, 
namely Macoma balthica, Mya arenaria and Cerastoderma glaucum. Among crustaceans Bathyporeia pilosa had the highest biomass. The biomass of other taxa did not exceed $5 \%$ of total biomass.

The biomass structure of invertebrate communities indicated a strong response to oiling as the matched pairs of oiled and reference sites diverged over time (second stage ANOSIM p < 0.05). Exposure and depth interactively affected the response of invertebrates to oiling (second stage BEST analysis, Spearman rank $r=0.49, p=0.042$ ). Sheltered and deeper sites were more sensitive to oiling than exposed and shallower sites. The biomass of deposit feeders has clearly increased in areas adjacent to heavier oil loads. The biomass of herbivores has tremendously declined in the sites of the most severe oil pollution. In the eastern part of Keibu Bay we failed to find any specimen of amphipod or isopod despite of intensive sampling. Similarly to deposit feeders, the biomass of suspension feeders has increased in impact areas whereas the values have decreased in reference areas.

The biomass structure of invertebrate communities significantly differed between 2006 and 2007 (ANOSIM $p<0.05$ ) and this difference reflected environmental variability other than exposure to oil. Actually, the coastal environment was fully recovered within $1.5 \mathrm{yr}$ after the spill as the matched pairs of oiled and reference sites converged over time (second stage ANOSIM p > $0.05)$.

The spatial modelling identified large areas along the southern coast of western and eastern Gulf of Finland those were highly sensitive to oil pollution. The values were lower and less variable in the central Gulf of Finland. Altogether $20 \%$ of the

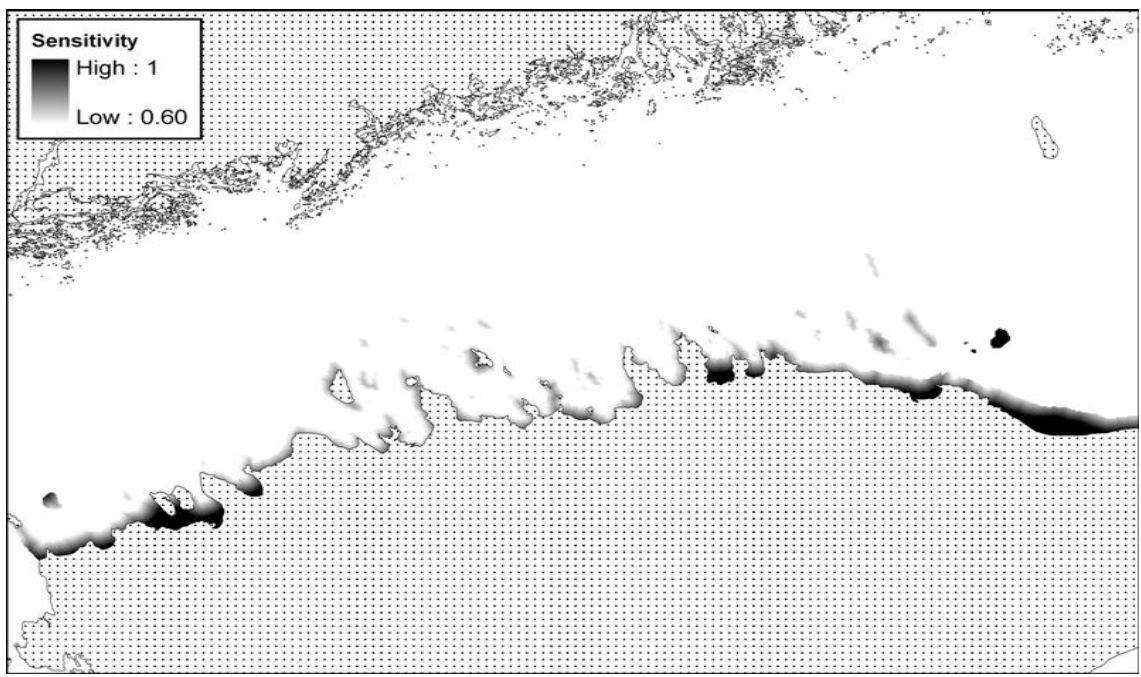

Figure 1: Probability distribution of the sensitivity of benthic invertebrate communities to oil spill along the southern coast of the Gulf of Finland (Baltic Sea). The values above 0.95 indicate significant impact. 
gulf was sensitive to oil spill (model probabilities $>0.95$ ). The spatial model described $81 \%$ of the overall variability of community (fig. 1).

\section{Discussion}

The impacts of oil spills to biological communities are difficult to predict because physical conditions interact with the community response. Furthermore biological systems are complex and impacts often result from indirect effects rather than direct toxicological impacts [1]. Often factors other than oil largely determine community structure resulting in confounded effects of the spill. Thus, the study designs that do not include the measurement of other environmental factors or lack the baseline data must be interpreted with particular care [2, 30].

As our study involved the key environmental variables and the structure of invertebrate communities in the design we were able to separate the effects of oil spills from other environmental forcing (both abiotic and biotic) and identify the interactive effects of oil spill and environmental variability on invertebrate communities. We examined the effect of the spill on the nearshore benthic community and followed the recovery of the community for a period of $1.5 \mathrm{yr}$ after the spill. In general, oil spill had significant effect on the variability of benthic invertebrate communities and the extent and direction of the impact varied among invertebrate feeding groups. The reaction of invertebrates to oil pollution was similar to moderate organic pollution [31-34] being exemplified by decrease in diversity, reduction of phytophilous species and increase in pollution tolerant species as observed recently in many other Estonian coastal areas [35]. The magnitude of oil spill was likely not so large to induce strong intoxification reaction due to the formation of $\mathrm{H}_{2} \mathrm{~S}$ [36].

The deposit feeders were likely gain due to the increase of organic matter in the system [20, 36]. The prevailing clam Macoma balthica is known to be extremely tolerant to oil exposure and can benefit from spills [20]. The herbivores in turn were severely decimated, namely the mobile herbivore species. We believe that herbivores such as amphipods and isopods were negatively affected due to characteristics of their escape behaviour and hydrophobic properties of their body [20, 37, 38]. The decline of amphipods is also known to be the most consistent pattern of previous oil spills [12, 39]. The positive effect of oil pollution to suspension feeders may be linked to increased phytoplankton productivity adjacent to the sites of the most severe oil pollution. Similar blooms of phytoplankton have been earlier documented in sites affected by oil pollution and have been explained by reduced grazing pressure by pelagic grazers [40]. Thus, the improved feeding regime [41] may shade the potential negative effects of oil spill on the suspension feeders [42].

The high recovery potential of benthic communities is supported by high exposure [1] of the study area. Rapid recovery is also expected due to very strong seasonality of the Baltic Sea, strong physical disturbance and short generation times of most coastal animal species [43]. The most impacted group, mobile herbivores, have large mobility and high reproduction potential [44] and therefore can be quickly restored through the immigration from the adjacent unimpacted bays. 


\section{Conclusions}

1) This study demonstrated that the spatial predictive modelling is a useful and cost-efficient tool in oil spill management as the modelled layers provide managers the possibility to reduce the overall environmental impact of future oil spills. The impacts of oil spill were strongest at sites that were most protected from waves but also deeper areas.

2) Predictive modelling provides managers a useful and cost-efficient tool in reducing the potential oil spill related environmental risk by e.g. redirecting shipping away from high sensitivity and low recovery potential sites, and by allocating sufficient oil combating resources to protect those areas in a case of oil accident.

\section{Acknowledgements}

This paper was prepared with funding support provided by European Regional Development Fund (ERDF) through INTERREG III A Southern Finland and Estonia program OILECO project "Integrating ecological values in the decision making process on oil spill combating in the Gulf of Finland", by target financed project SF $0180013 \mathrm{~s} 03$ of the Estonian Ministry of Education and Research and by the Estonian Science Foundation grants 6015 and 6016.

\section{References}

[1] Peterson, C.H., Rice, S.D., Short, J.W., Esler, D., Bodkin J.L., Ballachey B.E. \& Irons, D.B. Long-term ecosystem response to the Exxon Valdez oil spill. Science 302, pp. 2082-2086, 2003.

[2] Paine R.T., Ruesink, J.L., Sun, A., Soulanille, E.L., Wonham, M.J., Harley, C.D.G., Brumbaugh, D.R. \& Secord, D.L. Trouble on Oiled Waters: Lessons from the Exxon Valdez Oil Spill. Annual Review of Ecology and Systematics 27, pp. 197-235, 1996.

[3] Peterson, C.H. The 'Exxon Valdez' oil spill in Alaska: acute, indirect and chronic effects on the ecosystem. Adv Mar Biol, 39, pp. 1-103, 2001.

[4] Gundlach, E.R., Boehm, P.D., Marchand, M., Atlas, R.M., Ward, D.M. \& Wolfe, D.A. The fate of Amoco Cadiz oil spill. Science 221, pp. 122-131, 1983.

[5] Dauvin, J.C. 1998. The fine sand Abra alba community of the Bay of Morlaix twenty years after the Amoco Cadiz oil spill. Mar Pollut Bull 36, pp. 669-676, 1998.

[6] HELCOM, Manual for Marine Monitoring in the COMBINE Programme of HELCOM. 2006. http://sea.helcom.fi/Monas/CombineManual2/ CombineHome.htm

[7] Pimm, S.L. The complexity and stability of ecosystems. Nature 307, pp. 321-326, 1984.

[8] Olsgard, F. \& Gray, J.S. A comprehensive analysis of the effects of offshore oil and gas exploration and production on the benthic communities 
of the Norwegian continental shelf. Mar Ecol Prog Ser 122, pp. 277-306, 1995.

[9] Peterson C.H., Kennicutt, M.C. II, Green, R.H., Montagna, P., Harper, D.E. Jr., Powell, E.N. \& Roscigno, P.F. Ecological consequences of environmental perturbations associated with offshore hydrocarbon production: a perspective on long-term exposures in the Gulf of Mexico. Can. J. Fish. Aquat. Sci. 53, pp. 2637-2654, 1996.

[10] Pearson T.H. \& Rosenberg, R. Macrobenthic succession in relation to organic enrichment and pollution of the marine environment. Oceanogr mar Biol Annu Rev 16, pp. 229-311, 1978.

[11] Ibanez, F. \& Dauvin, J.C. Long-term changes (1977-1987) in a muddy fine sand Abra alba-Melinna palmata community from the Western English Channel: multivariate time-series analysis. Mar Ecol Prog Ser 49, pp. 6581. 1988.

[12] Jewett, S.C., Dean, T.A., Smith, R.O. \& Blanchard, A. Exxon Valdez oil spill: impacts and recovery in the soft-bottom benthic community and in adjacent to eelgrass beds. Marine Ecology Progres Series 185, pp. 59-83, 1999.

[13] Sousa, W. P. The role of disturbance in natural communities. Annu Rev Ecol Syst 15, pp. 353-391, 1984.

[14] Kotta, J., \& Møhlenberg, F. Grazing impact of Mytilus edulis L. and Dreissena polymorpha (Pallas) in the Gulf of Riga, Baltic Sea estimated from biodeposition rates of algal pigments. Ann Zool Fenn 39, pp. 151$160,2002$.

[15] Granéli, E., \& Sundbäck, K. The response of planktonic and microbenthic algal assemblages to nutrient enrichment in shallow coastal waters, southwest Sweden. J Exp Mar Biol Ecol 85, pp. 253-268, 1985.

[16] Kotta, J., H. Orav-Kotta, T. Paalme, I. Kotta, \& Kukk, H. Seasonal changes in situ grazing of the mesoherbivores Idotea baltica and Gammarus oceanicus on the brown algae Fucus vesiculosus and Pylaiella littoralis in the central Gulf of Finland, Baltic Sea. Hydrobiologia 554, pp. 117-125, 2006.

[17] Lauringson, V. \& Kotta, J. Influence of the thin drift algal mats on the distribution of macrozoobenthos in Kõiguste Bay, NE Baltic Sea. Hydrobiologia 554, pp. 97-105, 2006.

[18] Tillin, H. M., J. G. Hiddink, S. Jennings, \& Kaiser, M. J. Chronic bottom trawling alters the functional composition of benthic invertebrate communities on a sea-basin scale. Mar Ecol Prog Ser 318, pp. 31-45, 2006.

[19] Sanders, H.L., Grassle, J.F., Hampson, G.R., Morse, L.S., Garner-Price, S. \& Jones, C.C., Anatomy of an oil spill: long-term effects from the grounding of the barge Florida off West Falmouth, MA. J Mar Res 38, pp. 265-380, 1980.

[20] Elmgren R., Hansson S., Larsson U., Sundelin B. \& Boehm P D. The Tsesis oil spill: acute and long-term impact on the benthos. Marine Biology 73, pp. 51-65, 1983. 
[21] Kotta, J., Martin, G. \& Aps, R. Sensitivity of benthic vegetation and invertebrate functional guilds to oil spills and its use in oil contingency management related negotiation processes. Proc Estonian Acad Sci Biol Ecol, 56, pp. 255-269, 2007.

[22] Wiens, J.A. \& Parker, K.R. Analyzing the effects of accidental environmental impacts: Approaches and assumptions. Ecological Applications 5, pp. 1069-1083, 1995.

[23] Kotta, J., Kotta, I. \& Kask, J. Benthic animal communities of exposed bays in the outermost part of the Gulf of Finland. Proc Estonian Acad Sci Biol Ecol, 48, pp. 107-116, 1999.

[24] Bonsdorff, E. \& Pearson, T. H. Variation in the sublittoral macrozoobenthos of the Baltic Sea along environmental gradients: a functional-group approach. Australian J Ecol, 24, pp. 312-326, 1999.

[25] ArcGIS 9. Getting started with ArcGIS. ESRI, 2004.

[26] Clarke, K. R., \& Gorley, R. N. Primer v6. User Manual/ Tutorial. Primer-E, Plymouth, UK, 2006.

[27] Clarke, K. R., Somerfield, P. J., \& Chapman, M. G. On resemblance measures for ecological studies, including taxonomic dissimilarities and a zero-adjusted Bray-Curtis coefficient for denuded assemblages. $J$ Exp Mar Biol Ecol 330, pp. 55-80, 2006.

[28] Lehmann, A., Overton, J.M. \& Leathwick, J.R. GRASP: Generalized regression analysis and spatial predictions. Ecological Modelling, 157, pp. 189-207, 2002.

[29] Insightful. S-PLUS 6 for Windows User's Guide. Insightful Corporation, Seattle, WA, USA. 2001.

[30] Gelin, A., Gravez, V. \& Edgar, G.J. Assessment of Jessica oil spill impacts on intertidal invertebrate communities. Marine Pollution Bulletin 46, pp. 1377-1384, 2003.

[31] Leppäkoski, E. Assessment of degree of pollution on the basis of macrozoobenthos in marine and brackish-water environments. Acta Acad. Aboensis, Ser B Math et Phys, 35, pp. 1-90, 1975.

[32] Spies, R. B., Hardin, D. D. \& Toal, J. P. Organic enrichment or toxicity? A comparison of the effects of kelp and crude oil in sediments on the colonization and growth of benthic infauna. J Exp Mar Biol Ecol, 124, pp. 261-282, 1988.

[33] Josefson, A. B. Increase of benthic biomass in the Skagerrak-Kattegat during the 1970s and 1980s - effects of organic enrichment? Mar Ecol Prog Ser, 66, pp 117-130, 1990.

[34] Heip, C. Eutrophication and zoobenthos dynamics. Ophelia, 41, pp. 113 136, 1995.

[35] Kotta, J., Kotta, I. \& Viitasalo, I. Effect of diffuse and point source nutrient supply on the low diverse macrozoobenthic communities of the northern Baltic Sea. Bor Envir Res, 5, pp. 235-242, 2000.

[36] Berge, J. A. Macrofauna recolonization of subtidal sediment. Experimental studies on defaunated sediment contaminated with crude oil in two 
Norwegian fjords with unequal eutrophication status. I. Community responses. Mar Ecol Prog Ser, 66, pp. 103-115, 1990.

[37] Notini, M. Long-term Effects of an Oil Spill on Fucus Macrofauna in a Small Baltic Bay. J Fish Res Board Can, 35, pp. 745-753, 1978.

[38] Bonsdorff, E. \& Nelson, W. G. Fate and effects of Ekofisk crude oil in the littoral of a Norwegian fjord. Sarsia, 66, pp. 231-240, 1981.

[39] Gómez Gesteira, J.L. \& Dauvin, J.C. Amphipods are good bioindicators of the impact of oil spills on soft-bottom macrobenthic communities. Marine Pollution Bulletin 40, pp. 1017-1027, 2000.

[40] Johnsson, S., Larsson, U. \& Boehm, P. The Tsesis oil spill: Impact on the pelagic ecosystem. Mar. Pollut. Bull., 11, pp. 284-293, 1980.

[41] Lauringson, V., Mälton, E., Kotta, J., Kangur, K., Orav-Kotta, H. \& Kotta, I. Environmental factors influencing the biodeposition of the suspension feeding bivalve Dreissena polymorpha (Pallas): comparison of brackish and fresh water populations in the Northern Baltic Sea and Lake Peipsi. Estuarine Coast. Shelf Sci, 75, pp. 459-467, 2007.

[42] Tedengren, M. \& Kautsky, N. Comparative stress response to diesel oil and salinity changes of the blue mussel, Mytilus edulis from the Baltic and North seas. Ophelia, 28, 1-9. 1987.

[43] Hällfors, G., Å. Niemi, H. Ackefors, J. Lassig \& E. Leppäkoski, Biological oceanography. In Voipio, A. (ed), The Baltic Sea. Elsevier Oceanography Series, Amsterdam, 30, pp. 219-274, 1981.

[44] Chambers, M. R. The population ecology of Gammarus tigrinus (Sexton) in the reed beds of the Tjeukemeer. Hydrobiologia, 53, pp. 155-164, 1977. 